\title{
Maintenance strategies and local impact of MSW incinerators
}

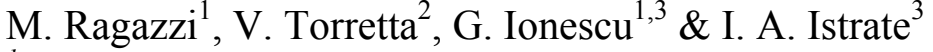 \\ ${ }^{1}$ Department of Civil, Environmental and Mechanical Engineering, \\ University of Trento, Italy \\ ${ }^{2}$ DiSAT, Department of Science and High Technology, \\ Insubria University of Varese, Italy \\ ${ }^{3}$ Department of Energy Production and Use, \\ Politehnica University of Bucharest, Romania
}

\begin{abstract}
The present paper gives a contribution to the understanding of the effects of variations in maintenance scheduling on the environmental impact of municipal solid waste incinerators. The proposed approach allows a vision of their impact beyond the conventional balances. The characteristics of a selected case study were put forward and discussed. A plant proposed for a region in the North East of Italy was chosen for the scheduling effects analysis because of the long period of non-operation of each waste treatment line: 3 months per year as requested from the local environmental protection agency. The following effects were discussed on a yearly basis: maintenance stop fractionation, maintenance stop lasting, maintenance stop seasonal scheduling; the last aspect was discussed also at device level. The extreme scenario of seasonal stop gave the opportunity of assessing the highest reduction of yearly average impact from the stack, varying the season of maintenance: a reduction up to $23 \%$ could be obtained for the pollutants concentration contribution at ground level in the area of highest impact, comparing the worst case with the best case by a diffusive model. In the case of more common periods of stops for maintenance the reduction would be lower. The role of district heating must be taken into account too.
\end{abstract}

Keywords: environmental impact, incineration, maintenance, municipal solid waste, operation, scheduling. 


\section{Introduction}

Municipal solid waste (MSW) management is performed by a few options whose environmental impact must be minimized [1-3]. In this frame the environmental impact of an incinerator depends on many factors:

- Site characteristics (the local climatology strongly affects the local impact);

- Amount of residual MSW (RMSW) to be treated (the off-gas flow-rate is proportional to the amount of RMSW burnt, if its characteristics are steady);

- $\quad$ Lower Heating Value (LHV) of the RMSW (this parameter influence the off-gas flow-rate);

- Emission concentrations at the stack during operating conditions (keeping steady the off-gas flow-rate, the release of pollutants at the stack is proportional to the pollutants concentrations at the emission);

- Stack height (a higher stack fosters the pollutants dilution into the atmosphere);

- Off-gas velocity at the stack (higher values of this parameter favor the dilution);

- Off-gas temperature at the stack (this parameter is limited by the need of performing energy recovery, but it is clear that higher values foster dilution into the atmosphere);

- Yearly operating hours (keeping steady the amount of waste to be fed, a shorter working period causes an increase of the waste flow-rate, with consequences on the peaks of impact).

In the literature, an analysis of the effects of the operating hours scheduling is not common both for thermochemical processes $[4,5]$ and for biochemical processes [6-11]. The aim of this paper is to go beyond the analyses based on overall balances $[12,13]$.

In this work, a conventional solution of combustion was chosen and discussed before analyzing what changes must be faced with in the case of a nonconventional process.

In this frame, stack emissions have to comply with the limit values that are covered by Directive 2001/80/EC from large combustion plant [14, 15]. For waste thermal treatment alternative technologies, such as pyrolysis and gasification, emission limit values are covered by Directive 2010/75/EU 2010 on industrial emissions due to the fact that they are considered waste incineration plants if the by-products resulted from the process are subsequently incinerated. According to the article 33 of the above mentioned directive, the combustion plants which opt for the 'limited life time derogation' must frame in a specific number of operating hours due to their emission values higher than the one imposed by law. If they tend to continue operating after their end life agreement, they must meet the standard emission limit values for continuous operation. The emission limitations value are imposed taking into account several criteria such as: the year of construction before or after 2006, type of turbine, type of energy produced, types of fuel used etc.. It is clear that the sector offers a wide set of 
scenarios, but, in the sector of RMSW energy valorization the most common option is the one based on direct combustion with continuous operation.

The present paper does not consider neither the role of the input variations in an existing plant [16] nor the role of pre-treatments [17-19] as this work focuses on the local effects of a thermochemical plant. To this concern the present paper integrates a recent research presenting a comparison of the local impact of conventional and unconventional thermochemical processes [19].

\section{Material and methods}

The analysis of the effects of maintenance scheduling criteria on the local environmental impact of a RMSW incinerator was developed through the following steps:

- case study selection;

- maintenance stop fractionation analysis and

- maintenance stop lasting analysis on yearly basis;

- maintenance stop seasonal scheduling analysis;

- device maintenance scheduling analysis.

The case study to be found must have the following characteristics:

- the technology must refer to a proposed or existing conventional plant (combustion is the most adopted process for the RMSW thermal treatment);

- the selected plant must have the Best Available Technologies (BAT) for the emissions treated (the analysis carried out in this paper must be seen as a functional part of the local impact optimization, instead of an option that allow reducing the interventions on the off-gas treatment line);

- the waste fed in must be representative of the typical conditions of the MSW conditions, in an area where waste management is advanced;

- the plant capacity must be representative of a real scale case study;

- pollutants dispersion modelling should be already available, with an approach based on a deep analysis of the local weather characteristics;

- the modelling analysis must include the role of plant shutdowns; otherwise, a specific simulation regarding this condition must be done.

The critical analysis of the effects of maintenance stop fractionation must take into account the know-how of the sector in term of environmental performances of the plants during stop and go operations. On yearly basis the following aspects must be considered:

- the consequences on plant capacity (a reduced number of running hours per year means higher power, considering the same amount of waste treated per year);

- the consequences on plant costs (a higher power needed to face with a reduced number of operating days per year causes an increase in the capital costs of the plant);

- the consequences on peak environmental effects (due to higher power, the off-gas flow-rate increases; as the pollutants concentration limits are the 
same, the mass flow-rate at the stack is higher with a consequent increase in the ground level contribution to the pollutants concentrations).

The analysis of the effects of maintenance seasonal scheduling must take into account:

- for contaminants, with threshold effect, the direct consequences on the peak impacts; indeed, changing the season the pollutant dilution changes;

- in the case of seasonal district heating, the indirect effects; indeed this option allows decreasing the local concentrations of a few pollutants.

The analysis of the effects of maintenance stop scheduling at device level must refer to a representative pollutant and different strategies of the maintenance of the devices aimed to reduce its emission.

\section{Results and discussion}

The case study selected in this paper regards a plant, proposed for a province in the North-East of Italy, with a capacity of $240,000 \mathrm{t} \mathrm{y}^{-1}$ [20]. Recently the proposal has been significantly modified, also to take into account the improvement in MSW selective collection, but the plant layout presented previously has very interesting characteristics for the aims of this work. Indeed, a characteristic of the plant is the long period of non-operation of each RMSW treatment line: 3 months per year, set by the local authorities. A dispersion/deposition model was used [21] to assess the pollutant concentrations induced in the territory; the area of interest was divided in meshes; for each mesh an atmospheric dilution coefficient was calculated. This coefficient is a parameter $\left[\mathrm{s} \mathrm{m}^{-3}\right]$ that, when multiplied by the flux of pollutant at the stack $[\mathrm{g} / \mathrm{s}]$, gives the contribution to the concentration in ambient air at ground level $\left[\mathrm{g} \mathrm{m}^{-3}\right]$ referred to a selected period: one year in this paper. Multiple dilution coefficients can be defined referring to pollutants entirely in gas phase (e.g. $\mathrm{Hg}$ ) or in solid phase (e.g. dust) or as a mix (e.g. PCDD/F). In this paper only dilution coefficients assessed for the mesh of maximum impact were taken into account.

The temporary switching on and off periods can significantly affect the incineration optimal running conditions [22]. The consequences are different if we consider the contaminants without and with threshold effects.

In the first case we are talking about contaminants with carcinogenic effects (for instance Polychlorinated dibenzo-p-dioxins and polychlorinated dibenzofurans (PCDD/F) and a number of heavy metals). Their impact is considerable in the case of exposure to significant concentrations over long periods. Therefore, if their concentration at the stack increases by up to one order of magnitude for a few hours in a year, due to switching on and switching off periods, the total related impact will increase only a little, because the effect will be diluted over thousands of running hours.

One of the pathways of $\mathrm{PCDD} / \mathrm{F}$ formation from an incineration process is due to the incomplete combustion of the feed. PCDD/Fs are destroyed at temperatures above $850^{\circ} \mathrm{C}$ but for a full effective and complete combustion of particulate carbonaceous material a higher temperature should be achieved at a residence time higher that $1 \mathrm{~s}$ [23]. Bag filters and electrostatic precipitators are 
used to remove the particulate phase of PCDD/Fs from stationary sources, while activated carbon injection and catalytic destruction/oxidation are used to adsorb or destroy PCDD/Fs in the gaseous phase. Still it was observed that during stable combustion and advanced flue gas cleaning operations, RMSW incinerator emit an unexpected PCDD/F emission after breakdown or transient pause of the process [24]. The first step during the plant shutdown is to stop the waste feeding into the system. After the waste is consumed, the furnace temperature starts to decrease and auxiliary burners (oil or methane) are used to maintain temperature and combustion control. It was estimated that the shut-down process could take up one and half hour. The start-up process is more complex and could take up to 11 hours. The furnace is raised to $400^{\circ} \mathrm{C}$ after the first two hours then holds at this point for a further two hours before increasing temperature again at a slower rate to the operating temperature. The polluted emission from the shut-down and start-up process could be explained by the so called "memory effect" which represents a delayed emission of certain persistent organic pollutants (POPs), primarily associated with the particulate phase that gets trapped by impaction, interception or gravity settling on the inner walls of flue gas transfer lines and air pollution control systems or any other post combustion system attached to certain industrial thermal operations [25]. The memory effect manifests during start-up period or during incomplete combustion, even after several hours after the stabilization of the combustion process [26]). Li et al. [24] reported that the period under influence of memory effect for PCDD/Fs in aged filter bags was about 96 and 34 days in two different cases. Some recent studies conducted on boilers from waste incineration revealed that the concentration of PCDD/Fs increased by a whopping $>500$ times in bottom ash and 1.6 times in fly ash during start up over the steady state condition in the studied boiler. During shut down, however, the elevation of PCDD/F in bottom ash was marginal and there was an appreciable reduction of concentration in fly ash over steady state condition [25]. It was reported that normal operation and shutdown of an incinerator cause $41 \%$ of the annual emissions for PCDD/F attributed to planned start-ups in the operational year for the plant [22].

In the case of pollutants with threshold effects, an unfavorable combination of switching on and off periods, with weather conditions that are adverse to contaminant dilution, may transform the local impact of the plant (in terms of air quality pollution) from negligible to significant. To this concern a significant impact could be associated with a contribution to the ground level concentration of a pollutant higher than 5\% of the allowed by law [27]. Considering this aspect, the scheduled shutdown of a plant (or one of its lines) should take place during the least favorable season for pollutant dilution: generally that means in winter. One contraindication to this strategy is that, during the winter season, most plants achieve a local improvement in the total contaminants, thanks to the benefits of district heating. However, in the selected case study the highest impact is located in an area not interested by the planned district heating [21].

The general conclusion is that the local impact can be minimized by reducing shutdowns to a minimum, the optimal number per year being one (for each line) and with meteorology that can play an important role. 
The reduction of the number of running days per year, for each line, has a number of implications:

- keeping steady the quantity of treated wastes, the plant cost is higher because the hourly flow of waste fed into the plant $\left(\mathrm{t} \mathrm{h}^{-1}\right)$ increases;

- concerning the impact of pollutants without threshold effects, small differences related to the different weather conditions during the running periods could give slight differences, but the order of magnitude is expected not to change;

- the peak impact may change in a significant and unfavourable way; for instance, if a yearly shutdown is scheduled for 90 days, instead of 40 days, the related hourly impact can grow by a factor of 1.18 (obtained from the ratio 325/275).

In Table 1 six scenarios of maintenance strategy are presented, based on specific characteristics of the analyzed plant: a planned yearly maintenance stop of three months. The number of stops for each of the two lines was assumed one, giving a non-operating period of 90 days straight.

Table 1: Hypotheses of maintenance scheduling for the analyzed case study.

\begin{tabular}{|c|c|c|}
\hline Scenario & Line 1 - season of maintenance & Line 2 - season of maintenance \\
\hline 1 & Spring & Autumn \\
\hline 2 & Winter & Autumn \\
\hline 3 & Winter & Winter \\
\hline 4 & Summer & Spring \\
\hline 5 & Winter & Summer \\
\hline 6 & Summer & Summer \\
\hline
\end{tabular}

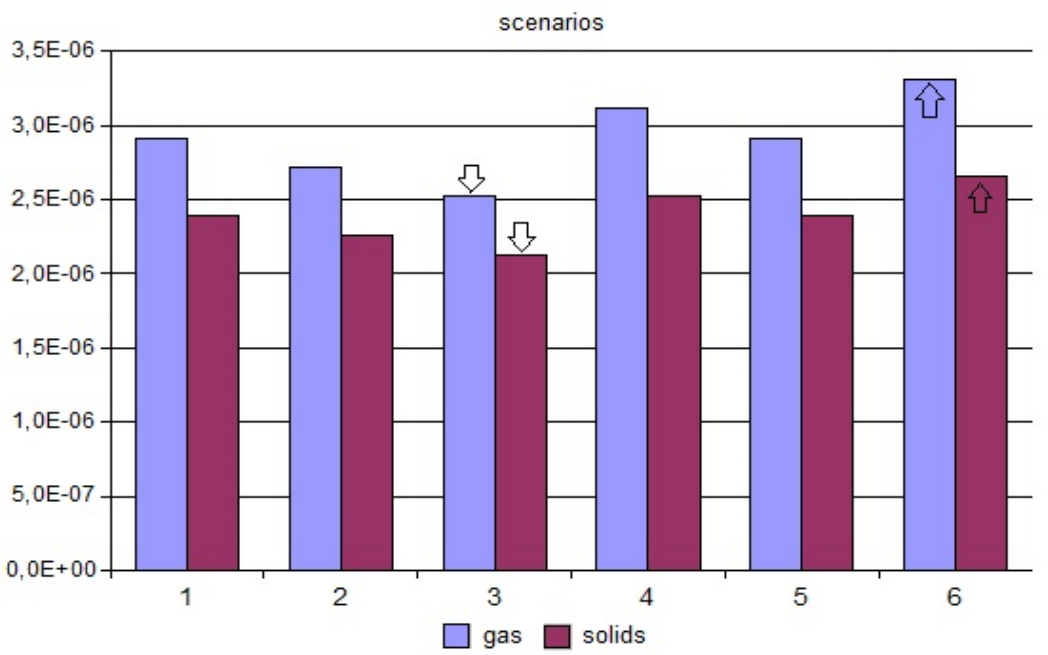

Figure 1: Dilution coefficients in the highest impact mesh (yearly average) $\left[\mathrm{s} / \mathrm{m}^{3}\right]$. 
In Figure 1 [21] the results of modeling are presented referring to the operation scenarios. The assessed dilution coefficients demonstrate that there is a significant difference of impact from the best and the worst scenario. These results must be discussed also taking into account that a district heating based on the energy from the plant can give positive local environmental balances that cannot be obtained when the plant is stopped. However, the analyzed case study has the mesh of highest impact not affected by the planned district heating. Considering the extreme scenarios, a reduction of up to $23 \%$ could be obtained. In case of more common period of stop for maintenance (lower than 90 days) this value would be lower.

The aim of significantly reducing nitrogen oxides and PCDD/F emissions, in the more recent incinerator plants, has led to the creation, or to the proposal, of off-gas treatment lines with SCR (Selective Catalytic Reduction) and SNCR (Selective Non Catalytic Reduction) systems. With SCR systems, plants can guarantee average daily PCDD/F values of $0.05 \mathrm{ng}_{\text {TEQ }} \mathrm{Nm}^{-3}$ (dry gas, $11 \% \mathrm{O}_{2}$ ).

This last value could decrease if a yearly average value were required; this approach would be more representative of the impact of this type of pollutant.

The simultaneous presence of an SNCR system allows setting a yearly average limit to be guaranteed, equal, for instance, to $0.03 \mathrm{ng}_{\text {TEQ }} \mathrm{Nm}^{-3}$. In such a set up of the plant, the manager could keep one line operating, while stopping only the SCR process for maintenance. In the case of pollutants that do not have a threshold effect, such as $\mathrm{PCDD} / \mathrm{F}$, the difference in the impact would be very small, over one year. It is different, however, for nitrogen oxides. Stopping the SCR system could significantly increase the plant impact on the territory, with respect to the hourly $\mathrm{NO}_{2}$ concentration. Thus, this operation should be scheduled in the period most favorable for pollutant dilution.

In the sector of MSW management the debate on the performances of conventional and novel thermo-chemical technologies is still relevant. A recent paper [26] has offered a multi-step approach, based on pollutant emission factors and atmospheric dilution coefficients, for a local comparative analysis of the contributions to local air pollution from different technologies. The selected processes concerned combustion, gasification and pyrolysis, alone or in combination. The pollutants taken into account were both carcinogenic and noncarcinogenic. The calculations in the cited paper were developed referring to a valley case-study; indeed mountain areas can suffer from a low diffusion of atmospheric pollutants; in spite of that, results demonstrated that the typical environmental performances of both conventional and innovative processes can give a contribution to the local air pollution adequately low even in sites located in critical areas. This result comes from more stringent emission regulations and process optimization. Differences among technologies resulted smaller than expected from promoters of novel processes; this is the consequence of the optimization of the direct combustion sector in the last decade.

No quantitative comparative considerations can be made, with the cited approach, referring to peak emissions; indeed the present literature does not offer adequate information for a comparison (the pollutant emission factors generally 
available are proposed for yearly environmental balances). In spite of that, some qualitative considerations can be made:

- innovative processes often require complex plants; complex configurations based on coupling more processes and more devices could be affected by a higher probability of unscheduled stops for maintenance; a higher number of transient periods of stop and go does not allow minimizing the local impact;

- gasification could have some advantages in terms of steadiness of emissions as the regulation of a device is easier when a gas and not a solid must be exploited energetically.

The challenges of the commercialization of a MSW gasifier come from the non-uniformity, heterogeneity, size and moisture of the feedstock. The waste chemical composition can cause problems in the downstream process due the gas contaminants (sulphur and nitrogen oxides, volatile mercury and other pollutants). In comparison with traditional combustion, the sub-stoichiometric atmosphere limits the formation of $\mathrm{PCDD} / \mathrm{F}$ and large quantities of $\mathrm{SO}_{\mathrm{x}}$ and $\mathrm{NO}_{\mathrm{X}}$ with smaller and less expensive gas cleaning equipment. The risk of $\mathrm{NO}_{\mathrm{X}}$ high emission comes with the syngas combustion or its utilization in a gas engine [28]. The processing costs of pre-treatment, conversion of MSW into Solid Recovered Fuel (SRF) and advanced flue gas cleaning might affect the overall economic balance. All these aspects, together with the high costs, keep still limited the presence of gasification in the MSW sector, that cannot take advantage yet of its potentially positive characteristics.

\section{Conclusions}

Some results pointed out in this paper, regarding the variability of the local impact as a consequence of changing a plant shutdown strategy, open the way for possible application, when calling for tenders, with the aim of obtaining from the future plant manager a correct strategy that minimizes the environmental incidence on the territory.

More in general, the role of start-up and shut-down should be taken into account carefully when the impact of a proposed plant must be assessed in an environmental impact study.

\section{References}

[1] Ghinea, C., Petraru, M., Bressers, H.Th.A., Gavrilescu, M. Environmental evaluation of waste management scenarios - Significance of the boundaries, Journal of Environmental Engineering and Landscape Management 20(1), pp. 76-85, 2012.

[2] Panepinto, D., Genon, G. Carbon dioxide balance and cost analysis for different solid waste management scenarios, Waste and Biomass Valorization 3(3), pp. 249-257, 2012.

[3] Ionescu, G., Zardi, D., Tirler, W., Rada, E.C., Ragazzi, M. A critical analysis of emissions and atmospheric dispersion of pollutants from plants 
for the treatment of residual municipal solid waste, Scientific Bulletin, 74(4), series D, pp. 227-240, 2012.

[4] Ragazzi M., Grigoriu M., Rada E.C., Malloci E., Natolino F. Risk assessment from combustion of sewage sludge treatment: three caste study comparison, Proceedings of Recent Advantages in Risk Management, Assessment and Mitigation, pp. 176-180, 2010.

[5] Ragazzi, M., Tirler, W., Angelucci, G., Zardi, D., Rada, E.C. Management of atmospheric pollutants from waste incineration processes: the case of Bozen, Waste Management \& Research 31(3), pp. 235-240, 2013.

[6] Rada E.C., Ragazzi M., Panaitescu V., Apostol T. Some research perspectives on emissions from bio-mechanical treatments of municipal solid waste in Europe, Environmental Technology 26(11), pp. 1297-1302, 2005.

[7] Rada E.C., Ragazzi M., Panaitescu V., Apostol T. The role of biomechanical treatments of waste in the dioxin emission inventories, Chemosphere, 62(3), pp. 404-410, 2006.

[8] Rada E.C., Franzinelli A., Ragazzi M., Panaitescu V., Apostol T. Modelling of PCDD/F release from MSW bio-drying, Chemosphere 68(9), pp. 16691674, 2007.

[9] Rada E.C. and Ragazzi M. Critical analysis of PCDD/F emissions from anaerobic digestion, Water Science and Technology 58(9), pp. 1721-1725, 2008.

[10] Rada E.C., Istrate I.A., Ragazzi M. Trends in the management of residual municipal solid waste, Environmental Technology 30(7), pp. 651-661, 2009.

[11] Rada E.C., Ragazzi M., Zardi D., Laiti L., Ferrari A. PCDD/F environment impact from municipal solid waste bio-drying plant, Chemosphere 84(3), pp. 289-295, 2011.

[12] Consonni S., Giugliano M., Massarutto A., Ragazzi M., Saccani C. (Material and energy recovery in integrated waste management systems: Project overview and main results, Waste Management 31(9-10), pp. 2057 2065, 2011.

[13] Ragazzi M., Rada E.C., Antolini D. Material and energy recovery in integrated waste management systems: An innovative approach for the characterization of the gaseous emissions from residual MSW bio-drying, Waste Management 31(9-10), pp. 2085-2091, 2011.

[14] Ciuta, S., Schiavon, M., Chistè, A., Ragazzi, M., Rada, E.C., Tubino, M., Badea, A., Apostol, T., Role of feedstock transport in the balance of primary PM emissions in two case-studies: RMSW incineration vs. sintering plant, Scientific Bulletin, 74(1), serie D, pp. 211-218, 2012.

[15] Morselli, L., Passarini, F., Piccari, L., Vassura, I., Bernardi, E. Risk assessment applied to air emissions from a medium-sized Italian MSW incinerator. Waste management \& Research 29(10), pp. 48-56, 2011.

[16] Ragazzi M. and Rada E.C. Effect of recent strategies of selective collection on the design of municipal solid waste treatment plants in Italy, WIT Transactions on Ecology and the Environment 109, pp. 613-620, 2008. 
[17] Cocarta D.M., Rada E.C., Ragazzi M., Badea A., Apostol T. A contribution for a correct vision of heath impact from municipal solid waste treatment, Environmental Technology 30(9), pp. 963-968, 2009.

[18] Negoi R.M., Ragazzi M., Apostol T., Rada E.C., Marculescu C. Bio-drying of Romanian Municipal Solid Waste: an analysis of its viability, Scientific Bulletin 71(4), serie C, pp. 193-204, 2009.

[19] Ragazzi M. and Rada E.C. Multi-step approach for comparing the local air pollution contributions of conventional and innovative MSW thermochemical treatments, Chemosphere 89(6), pp. 694-701, 2012.

[20] PAT - Provincia Autonoma di Trento - Autonomous Province of Trento 2003, www.provincia.tn.it - Accessed in February 2013.

[21] DICA - Dipartimento di Ingenegeria Civile e Ambientale - Civil and Environmental Engineering Department, Environmental Impact Assessment of the Ischia Podetti Thermochemical Plant. Report of the University of Trento, 2003.

[22] Tejima H., Nishigaki M., Fujita Y, Matsumoto A., Takeda N., Takaoka M. Characteristics of dioxin emissions at startup and shutdown of MSW incinerators, Chemosphere 66, pp. 1123-1130, 2007.

[23] McKay G., Dioxin characterisation, formation and minimisation during municipal solid waste (MSW) incineration: review, Chemical Engineering Journal 86, pp. 343-368, 2002.

[24] Li, H.W., Wang, L.C., Chena, C.C., Yang, X.Y., Chang-Chienc, G.P., Wu, E.M.Y., Influence of memory effect caused by aged bag filters on the stack PCDD/F emissions, Journal of Hazardous Materials 185, pp. 1148-1155, 2011.

[25] Trivedi, J., Majumdar, D., Memory effect driven emissions of persistent organic pollutants from industrial thermal processes, their implications and management: A review, Journal of Environmental Management 119, pp. 111-120, 2013.

[26] Wikstrom, E., Ryan, S., Touati, A., Andbrian, K., Gullett, B. In Situ formed soot deposit as a carbon source for polychlorinated dibenzo-p-dioxins and dibenzofurans, Environmental Science Technology 38, pp. 2097-2101, 2004.

[27] Ragazzi M. and Rada E.C. RDF/SRF evolution and MSW bio-drying, WIT Transactions on Ecology and the Environment 163, pp. 199-208, 2012.

[28] Ionescu, G., Mărculescu, C., Badea, A. Alternative solutions for MSW to energy conversion, Scientific Bulletin, 73(3), serie C, pp. 243-254, 2011. 